\title{
Latrodectism in New Caledonia: First Report of Presumed Redback Spider (Latrodectus hasselti) Envenomation
}

\author{
Claude Maillaud, MD; Hervé Jourdan, PhD; Ken Winkel, MBBS, BMedSci, PhD; Gaëlle Arnaud, MD; \\ Patrick Lafforgue, MD; Francis Durand, MD \\ From SAMU/SMUR/SAU/UHCD (Emergency Department), Centre Hospitalier Territorial de Nouvelle-Calédonie (New Caledonia Territorial \\ Hospital) (Dr Maillaud, Dr Durand), and Applied Zoology Laboratory, UMR CBGP, Institut de recherche pour le développement (Dr Jourdan), \\ Noumea Cedex, New Caledonia; Australian Venom Research Unit, Department of Pharmacology, University of Melbourne, Australia (Dr Winkel); \\ SAU/SAMU (Emergency Department), CHU de Nantes, France (Dr Arnaud); and Réanimation APHP, Hôpital de Garches, France (Dr Lafforgue).
}

\begin{abstract}
We describe a recent case of presumed redback spider (Latrodectus hasselti) envenomation observed near Noumea in New Caledonia. This is the first local reported case in this archipelago, where $L$. hasselti is currently considered a native species. We highlight the challenge of providing appropriate analgesia in this situation and believe that the use of specific redback spider antivenom should be considered in New Caledonia.
\end{abstract}

Key words: Latrodectus, latrodectism, redback spider, black widow, envenomation, antivenom, New Caledonia

\section{Introduction}

The envenomation syndrome caused by spiders of the genus Latrodectus, termed latrodectism, is well known in Australia, ${ }^{1-4}$ New Zealand, ${ }^{2}$ Southern Europe, ${ }^{5,6}$ the United States, ${ }^{7}$ the Republic of South Africa, ${ }^{8}$ and Madagascar. ${ }^{9}$ It may present with local or generalized features, notably pain that particularly affects the bite site with regional radiation, myalgia, and headache, in association with autonomic nervous system disturbances, including localized piloerection and sweating and systemic hypertension. Fatalities have been reported but appear to be extremely rare. ${ }^{1,6}$

The redback spider, Latrodectus hasselti, is widely distributed in Australia, where envenomation by this spider is common and the use of specific antivenom has been widespread since Wiener's work in the 1950s and 1960s. ${ }^{1-4,10,11}$ In New Caledonia, the local species was identified as L hasselti in the 1920s. ${ }^{12}$ However, despite the undoubted presence of Latrodectus spiders since that time, a literature review (PubMed search) performed on

Corresponding author: Claude Maillaud, MD, SAMU/SMUR/SAU/ UHCD (Emergency Department), Centre Hospitalier Territorial de Nouvelle-Calédonie, BP J5, 98849, Noumea Cedex, New Caledonia (e-mail: claudemaillaud@yahoo.com.au).
March 10, 2007, failed to identify any reports of envenomation in this country. Here we describe the first case of presumed latrodectism in New Caledonia caused by a local redback spider bite.

\section{Case Report}

On February 12, 2007, at approximately 7:00 PM, a 44year-old patient, hospitalized since January 24 , 2007, for weight reduction, was bitten by a spider on the posterior aspect of his right shoulder. The bite occurred in an outbuilding of the New Caledonia Territorial Hospital, located in Col de la Pirogue, nearly $30 \mathrm{~km}$ north of the main city of Noumea, surrounded by a midaltitude rainforest (Figure 1). The spider was hidden in the patient's clothes, and he unintentionally crushed it while sitting. The victim and 4 witnesses to the bite described a shiny black spider with an orange hourglass pattern on the abdomen, whose body was approximately $2 \mathrm{~cm}$ long and whose legs were 3 to $4 \mathrm{~cm}$ long without any visible hair. Further investigations conducted after the bite showed that this outbuilding was infested with several hundred redback spiders. Although the biting animal was not kept, one of us (H.J.) formally identified another specimen collected on the site a few days later as a 


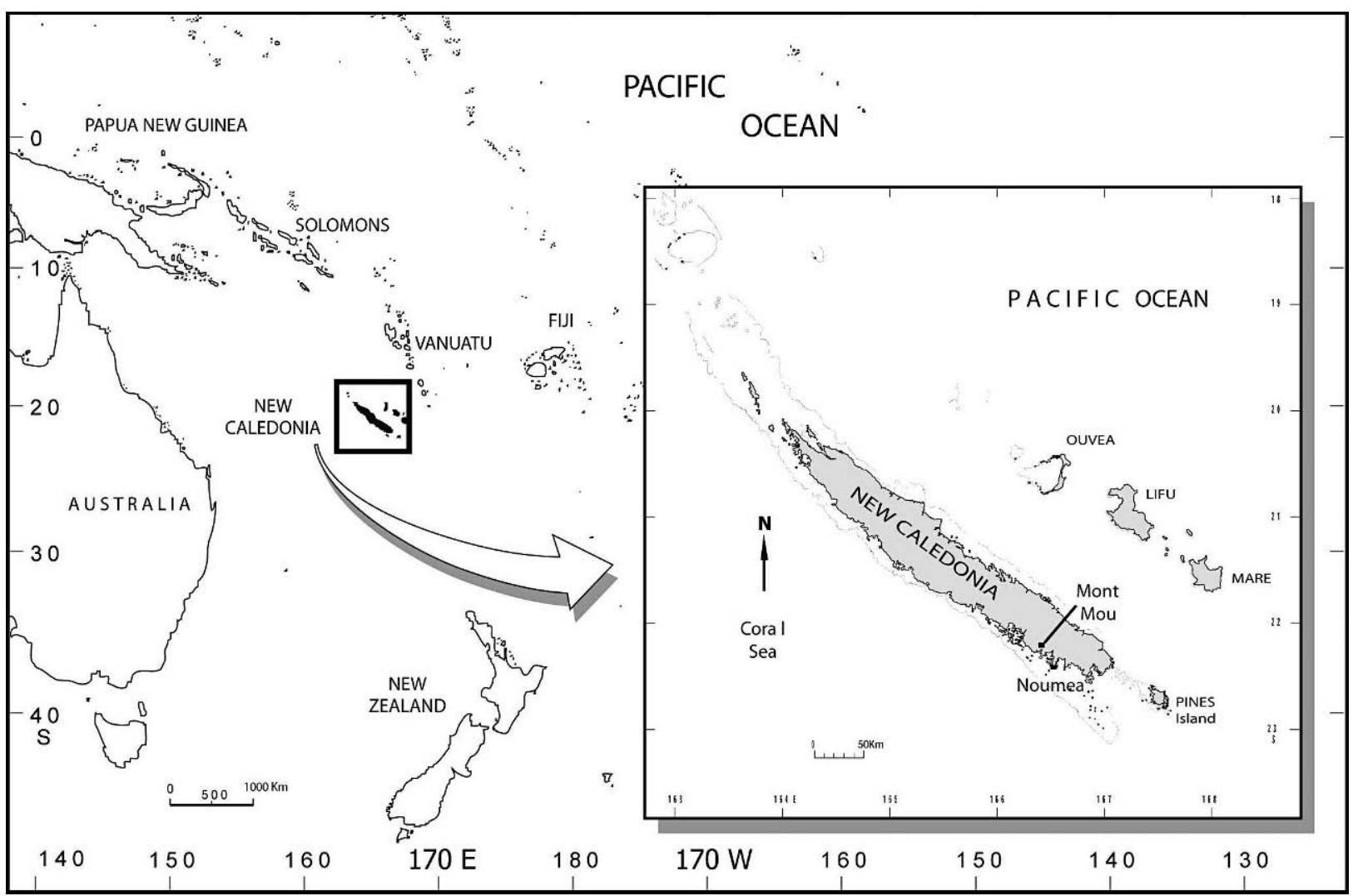

Figure 1. Situation map (photo H. Jourdan).

Latrodectus sp. Because only this species had been previously identified in the country, ${ }^{12}$ we supposed the collected spider to be $L$ hasselti (Figure 2).

The patient was first admitted to the Emergency Department of the New Caledonia Territorial Hospital 3 hours after the bite. At that time, he only complained of mild local pain. On examination, a slight $(1 \mathrm{~cm})$ noninflammatory edematous reaction was observed at the bite site. His blood pressure was $156 / 79 \mathrm{~mm} \mathrm{Hg}$, his pulse rate was 53, and other examinations were unremarkable, except for absent lower limb tendon reflexes, a finding related to some of the patient's past medical history (obesity, diabetes mellitus, hypertension, chronic nephritis, gout, and cervical spinal stenosis). Because his envenomation appeared, at this stage, rather mild and without systemic effects, the patient was sent back to the hospital outbuilding with a prescription of paracetamol and tramadol.

He was readmitted to the Emergency Department at 6:00 AM the following day, 11 hours after the bite, complaining of increasing pain involving the whole right shoulder, with intense waves of dysesthesias spreading to all limbs. The patient also appeared quite anxious, with restlessness peaking concomitantly with the pain parox- ysms. Hemodynamically he remained stable, and no fever was noted. Additional paracetamol and tramadol with added aqueous clonazepam did not relieve the pain.

Pain relief was eventually achieved using intravenous morphine. The patient was discharged from the Emergency Department by 11:00 AM with a prescription for paracetamol, tramadol, and clonazepam.

One of the authors (C.M.) followed up with the patient by telephone 2 weeks later. The patient reported a week of intense weakness after the bite (which he compared with the one he formerly experienced during a ciguatera poisoning) and that he had had to take 7 days of sick leave from work. He also suffered from intense pain affecting the 4 limbs, which persisted for 4 days before subsiding. He also mentioned that a reddish patch appeared at the bite site 24 hours after the bite and persisted for several days.

\section{Discussion}

Widow or comb-footed spiders of the genus Latrodectus (Araneae: Theridiidae) have a worldwide distribution; Latrodectus comprises 30 currently recognized species. ${ }^{13}$ Among them, 12 species are regularly involved in human envenomations. ${ }^{1-9}$ These spiders are commonly known 


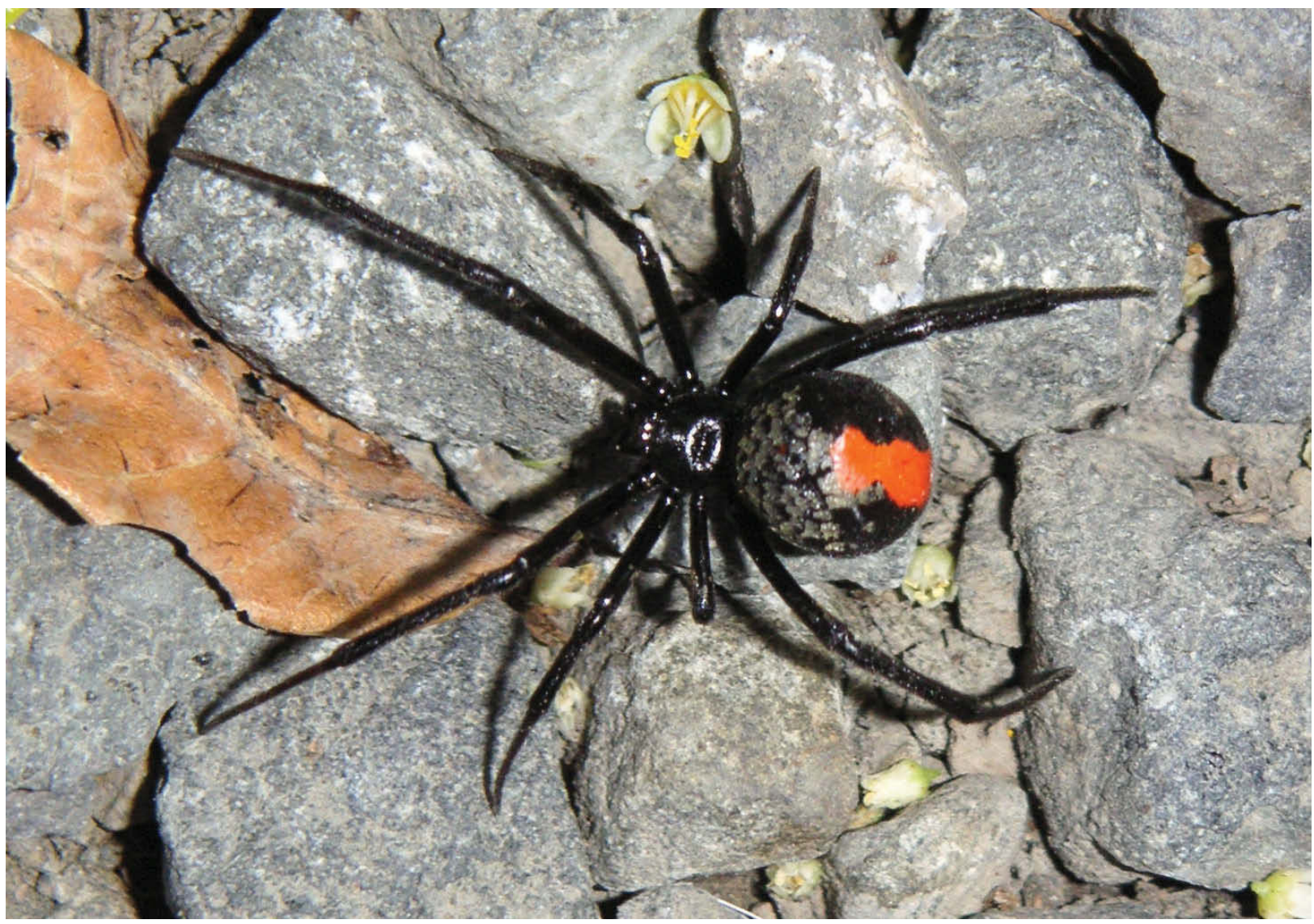

Figure 2. Caledonian Latrodectus hasselti (photo C. Maillaud).

as "black widows," except for the species Latrodectus geometricus, known as the "brown widow," and Latrodectus bishopi, the "red widow." In Australia, the local species, L. hasselti, is commonly referred to as the "redback spider." In French, the common name "veuve noire" is the exact translation of "black widow." Although French is the official language in New Caledonia, local people prefer to use the term "redback" rather than "veuve noire."

In New Caledonia, the local Latrodectus species has also been recorded as $L$. hasselti, and it is considered a native species. ${ }^{12}$ It is widely distributed, from sea level to nearly $1000 \mathrm{~m}$, mostly in open areas, including maquis shrub. It is also common on the Loyalty Islands. Except for this species, no other venomous spiders of any known medical significance are considered to inhabit New Caledonia. ${ }^{14}$ Thus, we suppose the presumptive identification to be correct, although we are aware that the biting specimen should have been collected to provide unequivocal evidence. It is also presumed that the 1924 species attribution by Berland remains accurate. ${ }^{12}$

Although no morphologic differences have been described between the Australia and New Caledonia redback spiders, major differences have been observed in behavioral traits between these 2 groups. Sexual cannibalism, commonly observed in Australian L. hasselti, has not been described in New Caledonia. Furthermore, the Australian spider is considered more aggressive against humans (Dr Robert Raven, oral communication, March 12, 2007). However, because taxonomic assignment of species in the genus may rely on slight differences in morphologic characters, genetic studies have shown to be of great value in defining species and phylogenic relationships among lineages in this order. ${ }^{13}$ We suggest that research using molecular characterization be considered to assess the identity of $L$ hasselti in New Caledonia.

Latrodectus are typically encountered in dark spaces, where they spin web wires that trail below their retreats (cavities). Some of these spiders, such as $L$ hasselti, are synanthropic, that is, found in human habitats (garden sheds, barns, urban and rural areas). Dense redback populations have been observed in Loyalty Islands colonizing various facilities, such as phone relays and electrical transformers. In this case, the envenomation followed an unusually high density of redbacks in a hospital outbuilding situated in a midaltitude rainforest. 
Latrodectus venom contains a potent presynaptic neurotoxin that provokes a massive acute release of neurotransmitters, particularly catecholamines, followed by a complete exhaustion of the neuromediator release, and alterations on small synaptic vesicles that last for weeks before fully recovery. ${ }^{15}$ This may explain the long duration of neurologic symptoms that is occasionally described, as seen in this case. In this and other clinical aspects, this case resembles those previously described in Australia, New Zealand, ${ }^{1-4}$ and other countries. ${ }^{5-9}$ Pain is usually the main symptom, localized at the bite site or spreading to limbs, back, chest, or abdomen, usually described as spasms or cramps, typically increasing over hours rather than minutes. Hypertension is a common feature but was not observed in this case, because the patient's blood pressure was similar to his prior baseline values. Restlessness and anxiety are reported less frequently. Prolonged weakness has been reported in cases of moderate to severe $L$ hasselti envenoming. ${ }^{1-9}$

The medications administered in this case appear to have been largely ineffective, although opiates succeeded in providing temporary pain relief. Paracetamol and tramadol were considered as an appropriate first-line therapy, because the pain was initially mild. Clonazepam was added because it is customarily used for neurogenic pain, considered relevant to the patient's condition. Intravenous morphine was used late, partly because the medical team was unfamiliar with the potential severity of pain in such envenomations. No prescription of oral opiates was given to the patient when discharged, because he was not suffering at that time and the possible persistence of symptoms was not obvious.

In general, analgesics are considered to be less effective than Latrodectus antivenom therapy. ${ }^{1,2,7,8,10}$ Nevertheless, some authors in Europe, where antivenom is no longer available, consider symptomatic treatments to be usually successful in mild envenomations. ${ }^{5}$ In the United States, antivenom side effects (including 1 fatality) have been described, and this therapy is therefore reserved for severe envenomations. ${ }^{7}$ On the other hand, lethal envenomations, now extremely rare, have only been reported where or when antivenom is unavailable or not given. ${ }^{11}$

Opiates, benzodiazepines, and myorelaxant drugs might be considered as an alternative to antivenom therapy. ${ }^{4-8}$ The current interest in calcium salts is controversial. $^{4-9}$

The use of redback spider antivenom (CSL Ltd, Parkville, Australia) was not considered in this case, although it was available at the hospital. This was partly due to a lack of familiarity among emergency medical staff regarding antivenom availability and indications for its use. Because of this case, Emergency Department medical staff has been provided detailed information about redback venom toxicity and the use of redback spider antivenom.

\section{Conclusions}

A Latrodectus species, considered to be L hasselti, the redback spider whose medical importance is well known in Australia, was found in New Caledonia. Residents of New Caledonia should be educated regarding Latrodectus envenoming and the availability of treatment for latrodectism. We suggest that local physicians be fully informed about the nature of the syndrome and that the indications for use of the specific antivenom be considered.

\section{Acknowledgments}

We acknowledge Dr Robert Raven, Queensland Museum, for his helpful advice. The AVRU acknowledges funding support from the Australian Government Department of Health and Ageing. CSL Ltd supports the provision of the AVRU 24/7 medical advisory service on the management of venomous bites and stings.

\section{References}

1. Wiener S. Red back spider bite in Australia: an analysis of 167 cases. Med J Aust. 1961;2:44-49.

2. Sutherland SK, Trinca JC. Survey of 2144 cases of redback spider bites: Australia and New Zealand, 1963-1976. Med J Aust. 1978;2:620-623.

3. Isbister GK, Gray MR. Latrodectism: a prospective cohort study of bites by formally identified redback spiders. Med J Aust. 2003;179:88-91.

4. Jelineck GA. Widow spider envenomation (latrodectism): a worldwide problem. Wilderness Environ Med. 1997;8:226231.

5. De Haro L, David JM, Jouglard J. Latrodectism in southern France: a series of cases from the poisoning center of Marseille [in French]. Presse Med. 1994; 23:11211123.

6. Maretic Z. Latrodectism: variations in clinical manifestations provoked by Latrodectus species of spiders. Toxicon. 1983;21:457-466.

7. Clark RF, Wethern-Kestner S, Vance MV, Gerkin R. Clinical presentation and treatment of black widow spider envenomation: a review of 163 cases. Ann Emerg Med. 1992;21:782-787.

8. Muller GJ. Black and brown widow spider bites in South Africa: a series of 45 cases. S Afr Med J. 1993;83:399405.

9. Ramialiharisoa A, De Haro L, Jouglard J, Goyffon M. Latrodectism in Madagascar [in French]. Med Trop. 1994; 54:127-130. 
10. Isbister GK, Graudins A, White J, Warrell D. Antivenom treatment in arachnidism. J Toxicol Clin Toxicol. 2003;41: 291-300.

11. Nimorakiotakis B, Winkel KD. Spider bite: the redback spider and its relatives. Aust Fam Physician. 2004;33:153157.

12. Berland L. Araignées de la Nouvelle-Calédonie et des Iles Loyalty. In: Sarasin F, Roux J, eds. Nova Caledonia, A. Zool. 3 (2). Berlin: Kreidels Verl; 1924:159-255.
13. Garb JE, Gonzalez A, Gillespie RG. The black widow spider genus Latrodectus (Araneae: Theridiidae): phylogeny, biogeography, and invasion history. Mol Phyl Evol. 2004;31:1127-1142.

14. Rageau J. Insectes et autres arthropodes d'intérêt médical ou vétérinaire en Nouvelle-Calédonie et aux Iles Loyauté. Etudes Mélanésiennes. 1956;10/11:60-103.

15. Grishin E. Polypeptide neurotoxins from spider venoms. Eur J Biochem. 1999;264:276-280. 